\title{
Prevalence of Non-Communicable Diseases and Number of Comorbidities According to Differences in Household Income Levels in Japan: Analysis from National Health and Nutrition Survey
}

\author{
Chika Horikawa ${ }^{1,2}$, Nobuko Murayama ${ }^{1}$, Asami Ota1 ${ }^{1}$, Megumi Tsuruta2 ${ }^{2}$, Satoshi Matsunaga', \\ Kazuya Fujihara' ${ }^{2}$, Osamu Hanyu' ${ }^{2}$, Hirohito Sone ${ }^{2}$ \\ ${ }^{1}$ Department of Health and Nutrition, Faculty of Human Life Studies, University of Niigata Prefecture, Niigata, Japan \\ ${ }^{2}$ Department of Hematology, Endocrinology, and Metabolism, Faculty of Medicine, Niigata University, Niigata, Japan \\ Email: horikawa@unii.ac.jp
}

How to cite this paper: Horikawa, C., et al. (2017) Prevalence of Non-Communicable Diseases and Number of Comorbidities According to Differences in Household Income Levels in Japan: Analysis from National Health and Nutrition Survey. Food and Nutrition Sciences, 8, 19-30. http://dx.doi.org/10.4236/fns.2017.81002

Received: October 18, 2016

Accepted: December 9, 2016

Published: December 12, 2016

Copyright $\odot 2017$ by authors and Scientific Research Publishing Inc. This work is licensed under the Creative Commons Attribution International License (CC BY 4.0).

http://creativecommons.org/licenses/by/4.0/

c) (i) Open Access

\begin{abstract}
Though it has been reported that in Western developed countries socioeconomic status is associated with non-communicable diseases (NCD), there are sparse evidence from Japan, midst an income gap that has been pointed out in recent years. Therefore, we examined the presence or absence of NCD and the number of comorbidities according to household income in Japanese, using data from the National Health and Nutrition Survey of 2010. 1287 men and 1659 women aged $20-79$ years from households at 3 income levels ( $<2,2-5.9, \geq 6$ million yen) were analyzed. Participants completed questionnaires regarding whether they had been diagnosed with $\mathrm{NCD}$, as well as undergoing clinical laboratory tests. Logistic regression analyses were used for statistical analysis with adjustment for age, gender, household size, and population of municipalities. The prevalences of participants with high, medium, and low income were $22.3 \%, 57.6 \%$, and $20.2 \%$, respectively. Participants with the lowest income had the highest odds of hypertension (OR [95\% confidence interval $(\mathrm{CI})]=1.71[1.29-2.26], p<0.001)$, diabetes (1.50 [1.02 - 2.20], $p=0.041)$, and stroke (5.07 [2.04 - 12.60] $p<0.001)$. Additionally, prevalences of participants with 2 or $3 \mathrm{NCD}$ (hypertension, diabetes, and hypercholesterolemia) were $15.0 \%$ and $33.0 \%$ in high and low income levels, respectively. A low income could contribute to a high prevalence of NCD and large number of comorbidities among Japanese. Establishing a health policy in Japan is needed to enable an optimal health condition and lifestyle regardless of socioeconomic disparities.
\end{abstract}

\section{Keywords}

Non-Communicable Diseases, Comorbidities, Household Income,

National Health and Nutrition Survey, Japan 


\section{Introduction}

Socioeconomic disparities cause health disparities, such as those related to environmental exposures [1], social environment [2], psychological characteristics [3], health care [4], lifestyle [5], and behavior [1] [6] and health disparities have become among the most serious problems on a global basis. According to some reports from Western developed countries, there showed that participants with low socioeconomic status have a high risk of obesity, diabetes mellitus, cardiovascular disease [7] [8] [9], and mortality [10]. Once a disease has developed, the cost of medical care constrains a lowincome individual's financial situation [11] and creates a vicious circle.

On the other hand, Japan is an Asian developed country that had relatively narrowed the gap between wealth and poverty compared to Western developed countries. About 30 years ago, it was declared that "almost all Japanese are middle-class" [12], however, the widening of the household income gap in more recent years in Japan is now considered a social problem, and the Gini coefficient of income inequality has increased [13]. Because of the growing interest in the effect of socioeconomic differences on health, a question on household income was added to the questionnaire of the National Health and Nutrition Survey (NHNS) in 2010.

Providing a scientific basis for the income gap in the Japanese population is of immediate importance in order to develop effective health policies relevant to increasing healthy life expectancy and improving ones' quality of life, considering the number of persons with non-communicable diseases (NCD) and medical expenses in Japan have been rapidly increasing in the last ten years [14] [15]. As shown by previous studies in Japan, a low socioeconomic position and relative income deprivation were significantly correlated with high mortality rates caused by cardiovascular disease and cancer [16] [17].

Nevertheless, evidence for the association between household income and the presence or absence of NCD is limited to studies based on household expenditures and relative income deprivation [18] [19] although NCD is a leading cause of death in Japan [20]. Moreover, there has been no evidence from research on the relationship between household income and number of comorbidities in Japan based on a nationwide setting. Therefore, we aimed this study to explore differences in the prevalence of NCD and the number of comorbidities according to household income from data of the NHNS.

\section{Methods}

\subsection{Participants}

Study participants were those who completed the NHNS. The NHNS, conducted in November 2010, included a lifestyle questionnaire survey, dietary intake survey, and physical examination. Participants aged from 1 year or older had measurements of height and weight and a dietary assessment and those aged 20 years or older additionally had blood tests and answered the question on household income. Detailed information regarding the NHNS were described elsewhere [21]. The NHNS is a survey conducted by the Japanese government based on the Health Promotion Law. Those administering this survey agreed to following the Declaration of Helsinki and the ethi- 
cal guidelines for medical and health research involving human subjects stipulated by the Ministry of Education, Culture, Sports, Science and Technology in Japan and the Ministry of Health, Labor and Welfare. Informed consent was obtained for all enrolled participants. The data obtained were published under the Statistics Act by the Japanese government. Our study was permitted to use the unlinkable anonymizing data by the Ministry of Health, Labor and Welfare for the purpose of this study (ID 0813-2 approved on August 13,2015). Participants in this study were 1287 men and 1659 women aged 20 - 79 years who completed the questionnaire, laboratory tests, and physical examination.

\subsection{Assessments of Participants}

Participants' characteristics were surveyed by a physical examination that included measurements of weight, height, body mass index (BMI), systolic blood pressure (SBP), and diastolic blood pressure (DBP) and laboratory tests to determine values for HbA1c, random blood glucose (RBG), serum HDL-cholesterol (HDL-C), serum LDL-cholesterol (LDL-C), and serum triglycerides (TG). Screening status for NCD including hypertension (HT), diabetes mellitus (DM), hypercholesterolemia (HC), stroke, and coronary heart disease (CHD) were obtained by self-reported questionnaires on whether participants had been diagnosed with any of those diseases and/or whether participants had been or were being treated with medication (antihypertensive agents, oral hypoglycemic agents and/or insulin, and cholesterol-lowering agents).

Household income per year was assessed by a question with four options (High: $\geq 6$ million yen, Middle: 2 - 5.9 million yen, Low: $<2$ million yen, and "Don't know"). Households that had non-responders or responders who selected multiple options were excluded from the current analysis. Other assessments included household size and population of municipalities (cities with populations of $\geq 150,000, \geq 50,000,<150,000$, or $<50,000)$.

\subsection{Statistical Analysis}

Participants' characteristics were described as mean $\pm \mathrm{SD}$ or percentage. The relationship of household income to clinical characteristics and nutritional intake were then examined using one-way ANOVA. Logistic regression analyses were used to estimate the adjusted odds ratios (OR) and 95\% confidence interval (CI) for whether participants had HT, diabetes, HC, stroke, or CHD. We also investigated ORs for the number of the following combinations of NCD according to household income level: HT and DM, HT and HC, DM and HC, and HT, DM, and HC. ORs were also investigated for stroke combined with 1 or more among HT, DM, and/or HC and CHD combined with at least 1 or more among HT, DM, and/or HC. Adjusted analyses were conducted with adjustment for age, gender, household size, and population of municipalities. All $\mathrm{p}$ values are two-sided, and the significance level is 0.05. All statistical analyses and data management were conducted using SPSS version 23 (IBM Corp., Armonk, NY, USA).

\section{Results}

Table 1 shows the characteristics of 2,946 participants according to household income. 
Table 1. Characteristics of the participants according to household income: National Health and Nutrition Survey, Japan, 2010.

\begin{tabular}{|c|c|c|c|c|c|}
\hline \multirow{2}{*}{$\begin{array}{l}\text { Household income } \\
\quad \text { (yen/year) }\end{array}$} & $\begin{array}{c}\text { Total } \\
(\mathrm{N}=2946)\end{array}$ & $\begin{array}{c}\text { High } \\
(\mathrm{N}=656)\end{array}$ & $\begin{array}{c}\text { Middle } \\
(\mathrm{N}=1696)\end{array}$ & $\begin{array}{c}\text { Low } \\
(\mathrm{N}=594)\end{array}$ & \multirow{2}{*}{$\begin{array}{c}p \\
\text { for } \\
\text { trend }\end{array}$} \\
\hline & Mean \pm SD & Mean \pm SD & Mean \pm SD & Mean \pm SD & \\
\hline Age (year) & $56.9 \pm 14.5$ & $52.0 \pm 12.7$ & $56.6 \pm 15.0$ & $63.3 \pm 12.7$ & $<0.001 \mathrm{a}$ \\
\hline Men (\%) & $43.7 \%$ & $40.8 \%$ & $46.3 \%$ & $39.1 \%$ & $0.032 \mathrm{~b}$ \\
\hline Height $(\mathrm{cm})$ & $159.3 \pm 9.2$ & $160.9 \pm 8.8$ & $159.8 \pm 9.1$ & $156.1 \pm 8.9$ & $<0.001 \mathrm{a}$ \\
\hline Weight (kg) & $59.1 \pm 11.6$ & $59.3 \pm 12.1$ & $59.7 \pm 11.7$ & $57.3 \pm 10.8$ & $<0.001 \mathrm{a}$ \\
\hline Body mass index $\left(\mathrm{kg} / \mathrm{m}^{2}\right)$ & $23.2 \pm 3.5$ & $22.7 \pm 3.4$ & $23.3 \pm 3.4$ & $23.4 \pm 3.5$ & $<0.001 \mathrm{a}$ \\
\hline Systolic blood pressure (mmHg) & $132.9 \pm 19.9$ & $128.0 \pm 19.0$ & $132.6 \pm 19.4$ & $139.3 \pm 20.3$ & $<0.001 \mathrm{a}$ \\
\hline Diastolic blood pressure $(\mathrm{mmHg})$ & $80.3 \pm 11.4$ & $79.6 \pm 11.4$ & $80.3 \pm 11.3$ & $81.1 \pm 11.8$ & $0.05 \mathrm{a}$ \\
\hline Random blood glucose (mg/dl) & $104.2 \pm 33.8$ & $99.6 \pm 25.7$ & $103.7 \pm 33.9$ & $110.5 \pm 40.2$ & $<0.001 \mathrm{a}$ \\
\hline HbAlc (\%) & $5.4 \pm 0.8$ & $5.4 \pm 0.7$ & $5.4 \pm 0.8$ & $5.5 \pm 0.9$ & $0.002 \mathrm{a}$ \\
\hline Total cholesterol (mg/dl) & $206.0 \pm 35.4$ & $207.8 \pm 34.6$ & $205.3 \pm 34.5$ & $206.2 \pm 38.5$ & $0.31 \mathrm{a}$ \\
\hline LDL-cholesterol (mg/dl) & $119.1 \pm 31.2$ & $119.9 \pm 30.7$ & $119.1 \pm 30.3$ & $117.9 \pm 34.0$ & $0.52 \mathrm{a}$ \\
\hline HDL-cholesterol (mg/dl) & $62.3 \pm 16.1$ & $64.3 \pm 16.3$ & $62.1 \pm 15.7$ & $60.5 \pm 16.8$ & $<0.001 \mathrm{a}$ \\
\hline Triglycerides (mg/dl) & $136.5 \pm 99.1$ & $133.3 \pm 96.3$ & $132.4 \pm 90.0$ & $151.8 \pm 122.7$ & $<0.001 \mathrm{a}$ \\
\hline Household size (person) & $3.0 \pm 1.5$ & $3.6 \pm 1.4$ & $3.0 \pm 1.5$ & $2.3 \pm 1.5$ & $<0.001 \mathrm{a}$ \\
\hline \multicolumn{6}{|c|}{ Population size of municipalities } \\
\hline \multicolumn{2}{|l|}{$<50,000(\%)$} & $19.5 \%$ & $57.9 \%$ & $22.6 \%$ & $0.002 b$ \\
\hline \multicolumn{2}{|l|}{$\geq 50,000-<150,000(\%)$} & $20.3 \%$ & $57.8 \%$ & $21.9 \%$ & \\
\hline \multicolumn{2}{|l|}{$\geq 150,000(\%)$} & $25.1 \%$ & $57.3 \%$ & $17.7 \%$ & \\
\hline
\end{tabular}

a. One-way ANOVA was used. b. Chi-square test was used. Household income (yen): high ( $\geq 6$ million), middle ( $\geq 2$ million and $<6$ million) and low ( $<2$ million).

Mean age of participants was 56.9 years and percentage of men was $43.7 \%$. Participants in the low household income group were significantly older and had significantly lower BMI, higher SBP, higher RBG and HbAlc, lower HDL-C, and higher TG compared with those with high household income. There was a significant association between low household income and small household size and small population of municipalities.

Table 2 shows the ORs for NCD of the participants according to household income. In the logistic regression model where adjustments were made for age, gender, household size, and population size of municipalities, the lowest household income was associated with a significantly high prevalence of HT (OR [95\% (CI)] $=1.71$ [1.29 to 2.26], $p<$ 0.001), DM (1.50 [1.02 to 2.20], $p=0.041$ ), and stroke (5.07 [2.04 to 12.60] $p<0.001$ ). There was no significant difference between household income and prevalence of HC ( $p$ for trend $=0.73$ ). When the participants at the middle and low income levels were combined, these participants had a 2.02 -fold prevalence of CHD compared with participants at a high income level $(p=0.045)$.

Table 3 shows the ORs for the number of prevalent NCD according to household 
Table 2. Odds ratios for prevalence of non-communicable diseases among participants according to household income: National Health and Nutrition Survey, Japan, 2010.

\begin{tabular}{|c|c|c|c|c|c|c|}
\hline \multirow{2}{*}{\multicolumn{2}{|c|}{$\begin{array}{c}\text { High }(\mathrm{N}=656) \\
\text { OR }\end{array}$}} & \multicolumn{2}{|c|}{ Middle $(\mathrm{N}=1696)$} & \multicolumn{2}{|c|}{ Low $(\mathrm{N}=594)$} & \multirow{2}{*}{$\begin{array}{c}p \\
\text { for } \\
\text { trend }\end{array}$} \\
\hline & & $\mathrm{OR}(95 \% \mathrm{CI})$ & $p$ value & $\mathrm{OR}(95 \% \mathrm{CI})$ & $p$ value & \\
\hline \multicolumn{7}{|l|}{ Hypertension } \\
\hline No. cases & $153(23 \%)$ & \multicolumn{2}{|l|}{$577(34 \%)$} & \multicolumn{2}{|l|}{$290(49 \%)$} & \\
\hline Not adjusted & 1.00 (Ref) & $1.70(1.38$ to 2.09$)$ & $<0.001$ & $3.14(2.46$ to 4.00$)$ & $<0.001$ & $<0.001$ \\
\hline Adjusted & 1.00 (Ref) & 1.25 (0.99 to 1.57$)$ & 0.06 & $1.71(1.29$ to 2.26$)$ & $<0.001$ & 0.001 \\
\hline \multicolumn{7}{|l|}{ Diabetes } \\
\hline No. cases & $53(8 \%)$ & \multicolumn{2}{|l|}{$229(14 \%)$} & \multicolumn{2}{|l|}{$112(19 \%)$} & \\
\hline Not adjusted & 1.00 (Ref) & 1.78 (1.30 to 2.43$)$ & $<0.001$ & $2.64(1.87$ to 3.74$)$ & $<0.001$ & $<0.001$ \\
\hline Adjusted & 1.00 (Ref) & $1.30(0.93$ to 1.81$)$ & 0.12 & $1.50(1.02$ to 2.20$)$ & 0.041 & 0.12 \\
\hline \multicolumn{7}{|c|}{ Hypercholesterolemia } \\
\hline No. cases & $227(35 \%)$ & \multicolumn{2}{|l|}{$635(37 \%)$} & \multicolumn{2}{|l|}{$260(44 \%)$} & \\
\hline Not adjusted & 1.00 (Ref) & $1.13(0.94$ to 1.37$)$ & 0.20 & $1.47(1.17$ to 1.85$)$ & 0.001 & 0.003 \\
\hline Adjusted & 1.00 (Ref) & $0.92(0.76$ to 1.13$)$ & 0.44 & $0.92(0.72$ to 1.19$)$ & 0.55 & 0.73 \\
\hline \multicolumn{7}{|l|}{ Stroke } \\
\hline No. cases & $6(1 \%)$ & $57(3 \%)$ & & $41(7 \%)$ & & \\
\hline Not adjusted & 1.00 (Ref) & 3.77 (1.62 to 8.78$)$ & 0.002 & 8.03 (3.38 to 19.06$)$ & $<0.001$ & $<0.001$ \\
\hline Adjusted & $1.00(\operatorname{Ref})$ & $2.74(1.15$ to 6.50$)$ & 0.022 & $5.07(2.04$ to 12.60$)$ & $<0.001$ & 0.001 \\
\hline \multicolumn{7}{|c|}{ Coronary heart disease } \\
\hline No. cases & $10(2 \%)$ & $77(5 \%)$ & & $28(5 \%)$ & & \\
\hline Not adjusted & $1.00(\mathrm{Ref})$ & 3.07 (1.58 to 5.97$)$ & 0.001 & $3.20(1.54$ to 6.64$)$ & 0.002 & 0.003 \\
\hline Adjusted & 1.00 (Ref) & $2.08(1.05$ to 4.16$)$ & 0.037 & 1.77 (0.81 to 3.87$)$ & 0.15 & 0.10 \\
\hline
\end{tabular}

Abbreviations: confidence interval, CI; odds ratios, OR. Adjusted analyses were conducted with adjustment for age, gender, household size, and population size of municipalities.

Table 3. Odds ratios for number of non-communicable diseases among participants according to household income: National Health and Nutrition Survey, Japan, 2010.

\begin{tabular}{|c|c|c|c|c|c|c|}
\hline & \multirow{2}{*}{$\begin{array}{c}\operatorname{High}(\mathrm{N}=656) \\
\text { OR }(95 \% \mathrm{CI})\end{array}$} & \multicolumn{2}{|c|}{ Middle $(\mathrm{N}=1696)$} & \multicolumn{2}{|c|}{ Low $(\mathrm{N}=594)$} & \multirow{2}{*}{$\begin{array}{c}p \\
\text { for } \\
\text { trend }\end{array}$} \\
\hline & & OR $(95 \% \mathrm{CI})$ & $p$ value & OR $(95 \% \mathrm{CI})$ & $p$ value & \\
\hline \multicolumn{7}{|c|}{ Having HT and DM } \\
\hline No. cases & $25(4 \%)$ & 140 & $(8 \%)$ & 76 & $(13 \%)$ & \\
\hline Not adjusted & 1.00 (Ref) & $2.27(1.47$ to 3.51$)$ & $<0.001$ & $3.70(2.32$ to 5.90$)$ & $<0.001$ & $<0.001$ \\
\hline Adjusted & 1.00 (Ref) & $1.54(0.98$ to 2.44$)$ & 0.06 & $1.87(1.12$ to 3.11$)$ & 0.017 & 0.06 \\
\hline \multicolumn{7}{|c|}{ Having $\mathrm{HT}$ and $\mathrm{HC}$} \\
\hline No. cases & $80(12 \%)$ & 294 & $(17 \%)$ & 154 & $(26 \%)$ & \\
\hline Not adjusted & 1.00 (Ref) & 1.51 (1.16 to 1.97$)$ & 0.002 & 3.14 (2.46 to 3.39$)$ & $<0.001$ & $<0.001$ \\
\hline Adjusted & 1.00 (Ref) & $1.14(0.86$ to 1.51$)$ & 0.36 & $1.46(1.05$ to 2.04$)$ & 0.025 & 0.05 \\
\hline
\end{tabular}




\section{Continued}

\begin{tabular}{|c|c|c|c|c|c|c|}
\hline \multicolumn{7}{|c|}{ Having DM and HC } \\
\hline No. cases & $29(4 \%)$ & 136 & $(8 \%)$ & 74 & $(12 \%)$ & \\
\hline Not adjusted & 1.00 (Ref) & $1.88(1.25$ to 2.84$)$ & 0.003 & $3.08(1.97$ to 4.80$)$ & $<0.001$ & $<0.001$ \\
\hline Adjusted & 1.00 (Ref) & $1.44(0.94$ to 2.21$)$ & 0.09 & $1.86(1.15$ to 3.02$)$ & 0.012 & 0.040 \\
\hline \multicolumn{7}{|c|}{ Having $\mathrm{HT}, \mathrm{DM}$ and $\mathrm{HC}$} \\
\hline No. cases & $18(3 \%)$ & 85 & $(5 \%)$ & 54 & $(9 \%)$ & \\
\hline Not adjusted & 1.00 (Ref) & 1.87 (1.12 to 3.14$)$ & 0.018 & $3.54(2.05$ to 6.12$)$ & $<0.001$ & $<0.001$ \\
\hline Adjusted & 1.00 (Ref) & $1.35(0.79$ to 2.31$)$ & 0.27 & $1.99(1.10$ to 3.61 & 0.024 & 0.044 \\
\hline \multicolumn{7}{|c|}{ Having stroke and at least 1 of $\mathrm{HT}, \mathrm{DM}$ and $\mathrm{HC}$} \\
\hline No. cases & $5(1 \%)$ & 55 & $(3 \%)$ & 37 & $(6 \%)$ & \\
\hline Not adjusted & 1.00 (Ref) & $4.36(1.74$ to 10.95$)$ & 0.002 & 8.65 (3.38 to 22.16$)$ & $<0.001$ & $<0.001$ \\
\hline Adjusted & 1.00 (Ref) & $3.21(1.25$ to 8.20$)$ & 0.015 & $5.58(2.08$ to 15.0$)$ & 0.001 & 0.001 \\
\hline \multicolumn{7}{|c|}{ Having CHD and at least 1 of HT, DM and HC } \\
\hline No. cases & $10(2 \%)$ & 67 & $(4 \%)$ & 26 & $(4 \%)$ & \\
\hline Not adjusted & 1.00 (Ref) & $2.66(1.36$ to 5.20$)$ & 0.004 & $2.96(1.41$ to 6.19$)$ & 0.004 & 0.010 \\
\hline Adjusted & 1.00 (Ref) & $1.79(0.89$ to 3.60$)$ & 0.10 & $1.66(0.75$ to 3.68$)$ & 0.21 & 0.26 \\
\hline
\end{tabular}

Abbreviations: confidence interval, CI; coronary heart disease, CHD; diabetes mellitus, DM; hypercholesterolemia, HC; hypertension, HT; odds ratios, OR. Adjusted analyses were conducted with adjustment for age, gender, household size, and population size of municipalities.

income level. The adjusted ORs for having HT and DM, HT and HC, and DM and HC among participants with a high income level compared with those with a low income level was 1.87 [1.12 to 3.11] ( $p=0.017), 1.46$ [1.05 to 2.04] $(p=0.025)$, and 1.86 [1.15 o 3.02] $(p=0.012)$, respectively. According to the presence of HT, DM, and HC, there was a significantly higher prevalence among participants at the low income level than at the high income level $(\mathrm{HR}[95 \% \mathrm{CI}]=1.99$ [1.10 to 3.61], $p=0.024)$. The prevalence of having stroke and at least 1 among HT, DM, and HC in participants with a low income level was also significantly higher compared with those with a high income level (HR $[95 \% \mathrm{CI}]=5.88$ [2.08 to 15.0$], p=0.001$ ). There was no significant difference between household income and prevalence of having $\mathrm{CHD}$ and at least 1 condition among HT, $\mathrm{DM}$, and $\mathrm{HC}(p=0.21)$.

Figure 1 shows the prevalences of HT, DM, and HC in participants according to household income level. The prevalences of participants with neither HT, DM, nor HC were $51.7 \%, 43.6 \%$, and $30.6 \%$ in the high, middle, and low income level, respectively. As to having 1 disease among $\mathrm{HT}, \mathrm{DM}$, and $\mathrm{HC}$, prevalences of participants at high, middle, and low income levels were $33.4 \%, 32.7 \%$, and $36.4 \%$, respectively. The prevalences of participants with 2 diseases among HT, DM, and HC were $12.3 \%, 18.5 \%$, and 23.9\%, and those with having all 3 diseases, HT, DM, and HC, were $2.7 \%, 5.0 \%$, and $9.1 \%$ in the high, middle, and low income level, respectively.]

\section{Discussion}

In this current study, we determined that there were differences in the prevalence of 


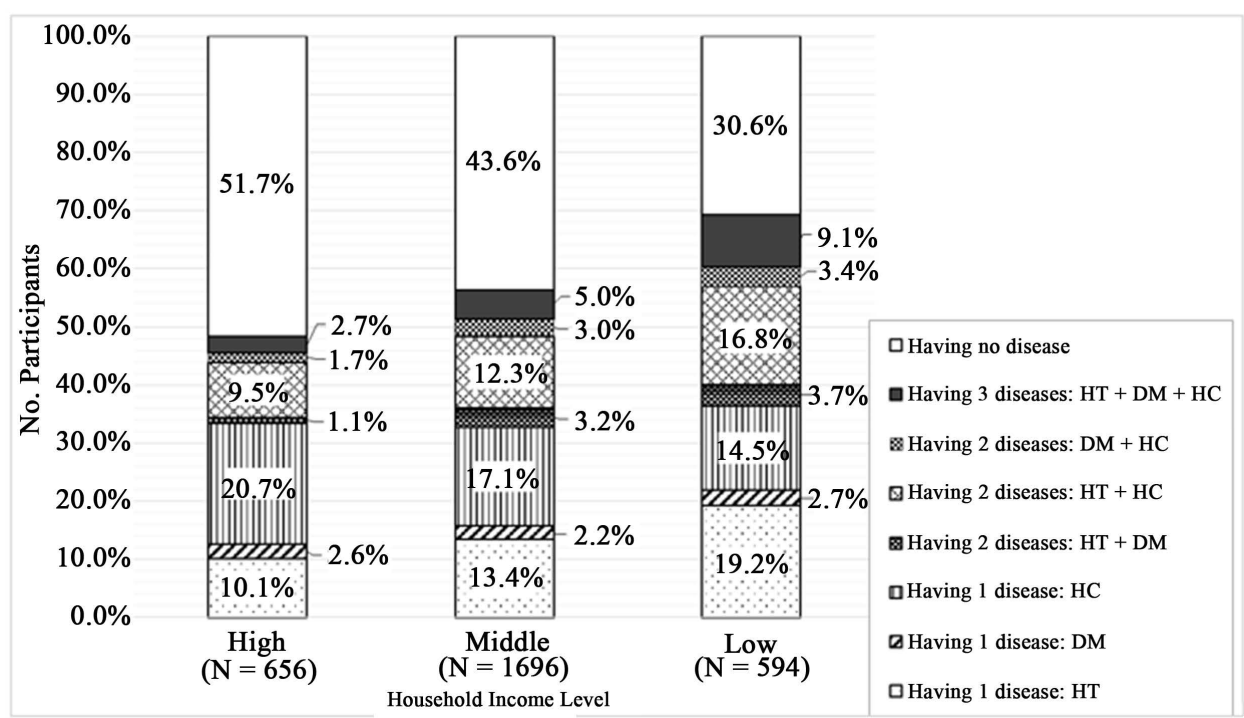

Figure 1. Summary of prevalence of hypertension, diabetes, and hypercholesterolemia of participants according to household income level: National Health and Nutrition Survey, Japan, 2010. Household income (yen): high ( $\geq 6$ million), middle ( $\geq 2$ million and $<6$ million) and low ( $<2$ million). Abbreviations: coronary heart disease, $\mathrm{CHD}$; diabetes mellitus, DM; hypercholesterolemia, HC; hypertension, HT.

NCD and the number of comorbidities according to household income in Japanese participants in the NHNS. High prevalence of NCD were observed in participants with a low household income, which supports previous reports from Western developed countries [7] [8] [9]. Of concern is that only $30.6 \%$ of participants with a low income was free from HT, DM, and $\mathrm{HC}$, but more than half at the high income level was free from these diseases. Participants with multiple risk factors have a greater risk of cardiovascular disease and mortality [22] [23] [24] [25]. Cardiovascular disease is the most common cause of death after cancer [20], therefore, proactive screening and control of NCD would be especially important for participants having a low income.

Although the current observational study could not reveal cause-effect relationships, plausible findings have been reported, suggesting reasons that a low household income is associated with NCD and a greater number of comorbidities. As for the association between income level and food intake in Japanese, we recently reported that household members with low and middle incomes had a significantly higher intake of cereals and a lower intake of vegetables, fruit, and fish compared with those with high incomes [26]. The price of grains and grain products is lower for supplying energy than foods such as fish, vegetables, and fruit according to market prices in Japan [27]. It is well known that vegetables and fruit are good sources of vitamins, minerals, and fiber, which are vital for maintaining health. For example, micronutrients, including vitamins and minerals, enable the optimal transformation of dietary energy sources such as carbohydrate, fat, and protein [28]. Vitamins, predominantly vitamins C and E, and carotenoids prevent organ damage by reactive oxygen species [29] [30]. Fibers slow gastric emptying and small bowel transit, interfere with the mixing of foodstuffs and digestive enzymes, and disrupt micelle formation [31], and have been associated with improved glucose metabolism [32]. As to fish, it is rich in omega-3 fatty acids, including eicosa- 
pentaenoic acid and docosahexaenoic acid, and these essential fats significantly decrease blood pressure and reduce inflammatory processes, vasoconstriction, and platelet aggregation, all known to be antiatherogenic [33] [34]. On the other hand, high consumption of foods such as grains that contain a high percentage of carbohydrates promotes high serum glucose [35] and TG levels but also promotes low HDL-C and LDL-C levels [36] [37] because of the relative reduction of fat intake relevant to cholesterogenesis. Considering the features of nutrients relevant to each food group and our current study that showed those with a low income level had high cereal intake and low vegetable, fruit, and fish intakes, it can be speculated that the characteristics of the dietary intake of Japanese with a low income level were related to their blood pressure and blood test values and were responsible for the high prevalence of HT, DM, and stroke.

Additionally, previous reports showed an association with a low income level and fewer occasions of regular physical activity and chronic stress than among those with higher incomes [38]. It is well recognized that an increment in physical activity improves blood pressure, blood glucose, blood lipids, and lipoproteins [39], and that chronic stress has an impact on neurotransmission and metabolism, resulting in elevations in blood pressure and blood glucose and enhanced lipoprotein synthesis [40]. Factors other than dietary habits need consideration in order to decrease NCD in persons with low incomes.

Once blood pressure control or the metabolic balance worsens caused by inappropriate intake of carbohydrate, fat, or protein and micronutrients resulting from the factors noted above, compensatory regulation occurs in metabolism for other nutritional and/or neurotransmitter activities caused by hormonal secretion [41] [42]. Therefore, the above-mentioned suggest reasons for the elevated prevalence of participants having multiple NCD in those with low income levels compared with high income levels.

Previous studies reported that persons with multiple chronic diseases have fair or poor general health and high psychological distress and feel dissatisfied, unhappy, or terrible about their lives [43] [44]. Furthermore, participants with multiple diseases incurred higher medical costs over a long duration than those without or having only 1 disease [45]. Therefore, the financial situations of low-income individuals would go from bad to worse in the presence of illness. Support for good control of NCD and for preventing onset of other diseases should be developed for low income Japanese.

In an effort to improve nutritional intake and metabolic characteristics related to NCD for people with low household income, Western developed countries are already using various approaches such as teaching skills for coping with stress and improving relationship skills [46], food aids such as food programs [47], and health coaching for lifestyle-style habits and preventing chronic disease [48] [49] [50]. These strategies were reported to be effective for participants to acquire appropriate knowledge and motivation and improve metabolic characteristics [46] [48] [49] [50]. However, practical research regarding health and nutrition policies for low-income Japanese is sparse. Moreover, we clarified that Japanese with a low income tended to have high carbohydrate and low animal fat and protein intake unlike low-income Western people. These results would be caused by differences between Asian and Western people in racial and 
ethnic-specific lifestyles and culture including dietary habits. Further studies are needed considering racial and ethnic-specific dietary patterns and lifestyle characteristics to explore effective health and nutrition policies, including those in Japan.

The present study had several limitations. First, as a cross-sectional study rather than a longitudinal or intervention study, we could not conclude cause-effect relationships as to how household income differences would affect NCD. Second, the potential for bias, such as response to a questionnaire on household income and whether having diseases or not, cannot be ruled out entirely although those who created the NHNS were public health experts. Another limitation is that the NHNS that included the questionnaire about household income and prevalence of NCD was first performed in 2010; therefore, we could not compare responses to the NHNS of previous years. The same survey should be routinely performed to monitor domestic situations.

\section{Conclusion}

In conclusion, we determined from responses to the NHNS that differences in income level would contribute to a high prevalence of NCD and a number of comorbidities in Japanese. Based on preliminary findings, further study is required to establish health policies that would enable an optimal health condition and lifestyle regardless of socioeconomic disparities.

\section{Acknowledgements}

This work was supported by a Health and Labour Sciences Research Grant, Japan (Comprehensive Research on Life Style-Related Diseases Including Cardiovascular Diseases and Diabetes Mellitus [H24-Jyunkankitou-Seisyu-Ippan-006]).

The research organizations that provided funding for this research did not have any role in the design and conduct of the study; correction, management, analysis, and interpretation of the data; or preparation, review, or approval of the manuscript. The authors declare that there is no conflict of interest associated with this manuscript.

\section{References}

[1] Pamuk, E., Makuc, D., Heck, K., et al. (1998) Socioeconomic Status and Health Chartbook. US Department of Health and Human Services, Washington DC.

[2] Sampson, R.J., Raudenbush, S.W. and Earls, F. (1997) Neighborhoods and Violent Crime: A Multilevel Study of Collective Efficacy. Science, 277, 918-924. https://doi.org/10.1126/science.277.5328.918

[3] Heinonen, K., Raikkonen, K., Matthews, K.A., et al. (2006) Socioeconomic Status in Childhood and Adulthood: Associations with Dispositional Optimism and Pessimism over a 21Year Follow-Up. Journal of Personality, 74, 1111-1126. https://doi.org/10.1111/j.1467-6494.2006.00404.x

[4] Adler, N.E., Boyce, W.T., Chesney, M.A., et al. (1993) Socioeconomic Inequalities in Health: No Easy Solution. Journal of the American Medical Association, 269, 3140-3145. https://doi.org/10.1001/jama.1993.03500240084031

[5] Winkleby, M.A., Cubbin, C., Ahn, D.K., et al. (1999) Pathways by Which SES and Ethnicity Influence Cardiovascular Disease Risk Factors. Annals of the New York Academy of Sciences, 896, 191-209. https://doi.org/10.1111/j.1749-6632.1999.tb08116.x

[6] Krebs-Smith, S.M., Cook, A., Subar, A.F., et al. (1995) US adults' Fruit and Vegetable In- 
takes, 1989 to 1991: A Revised Baseline for the Healthy People 2000 Objective. American Journal of Public Health, 85, 1623-1629. https://doi.org/10.2105/AJPH.85.12.1623

[7] Braveman, P.A., Cubbin, C., Egerter, S., et al. (2010) Socioeconomic Disparities in Health in the United States: What the Patterns Tell Us. American Journal of Public Health, 100, S186-S196. https://doi.org/10.2105/AJPH.2009.166082

[8] Eriksson, J.G., Forsén, T., Tuomilehto, J., et al. (2000) Early Growth, Adult Income, and Risk of Stroke. Stroke, 31,869-874. https://doi.org/10.1161/01.STR.31.4.869

[9] Andersen, I., Osler, M., Petersen, L., et al. (2003) Income and Risk of Ischaemic Heart Disease in Men and Women in a Nordic Welfare Country. International Journal of Epidemiology, 32, 367-374. https://doi.org/10.1093/ije/dyg073

[10] Pappas, G., Queen, S., Hadden, W., et al. (1993) The Increasing Disparity in Mortality between Socioeconomic Groups in the United States, 1960 and 1986. The New England Journal of Medicine, 329, 103-109. https://doi.org/10.1056/NEJM199307083290207

[11] Galbraith, A.A., Wong, S.T., Kim, S.E., et al. (2005) Out-of-Pocket Financial Burden for Low-Income Families with Children: Socioeconomic Disparities and Effects of Insurance. Health Services Research, 40, 1722-1736. https://doi.org/10.1111/j.1475-6773.2005.00421.x

[12] Large, S.S. (1998) Shōwa Japan: 1973-1989. Taylor \& Francis, Oxfordshire.

[13] OECD (2011) Divided We Stand Why Inequality Keeps Rising. OECD, Paris.

[14] Negishi, H. (2007) Life-Style Related Diseases, Metabolic Syndrome and Dietary Education. Asian Pacific Journal of Disease Management, 1, 41-53. https://doi.org/10.7223/apjdm.1.41

[15] Nozaki, M., Kashiwase, K. and Saito, I. (2014) Health Spending in Japan: Macro-Fiscal Implications and Reform Options. IMF Working Paper, International Monetary Fund, Washington DC.

[16] Fukuda, Y., Nakamura, K. and Takano, T. (2005) Cause-Specific Mortality Differences across Socioeconomic Position of Municipalities in Japan, 1973-1977 and 1993-1998: Increased Importance of Injury and Suicide in Inequality for Ages under 75. International Journal of Epidemiology, 34, 100-109. https://doi.org/10.1093/ije/dyh283

[17] Kondo, N., Saito, M., Hikichi, H., et al. (2015) Relative Deprivation in Income and Mortality by Leading Causes among Older Japanese Men and Women: AGES Cohort Study. Journal of Epidemiology and Community Health, 69, 680-685. https://doi.org/10.1136/jech-2014-205103

[18] Fukuda, Y. and Hiyoshi, A. (2012) Association of Income with Symptoms, Morbidities and Healthcare Usage among Japanese Adults. Environmental Health and Preventive Medicine, 17, 299-306. https://doi.org/10.1007/s12199-011-0254-6

[19] Fukuda, Y. and Hiyoshi, A. (2013) Associations of Household Expenditure and Marital Status with Cardiovascular Risk Factors in Japanese Adults: Analysis of Nationally Representative Surveys. Journal of Epidemiology, 23, 21-27. https://doi.org/10.2188/jea.JE20120021

[20] Statistics and Information Department Minister's Secretariat Ministry of Health, Labour and Welfare (2015) Handbook of Health and Welfare Statistics 2014. Health, Labour and Welfare Statistics Association, Tokyo.

[21] Ikeda, N., Takimoto, H., Imai, S., Miyachi, M. and Nishi, N. (2015) Data Resource Profile: The Japan National Health and Nutrition Survey (NHNS). International Journal of Epidemiology, 44, 1842-1849. https://doi.org/10.1093/ije/dyv152

[22] Jamison, D.T., Breman, J.G., Measham, A.R., et al. (2006) Disease Control Priorities in Developing Countries. 2nd Edition, World Bank, Washington DC.

[23] Grundy, S.M., Pasternak, R., Greenland, P., Smith, S. and Fuster, V. (1999) Assessment of Cardiovascular Risk by Use of Multiple-Risk-Factor Assessment Equations: A Statement for Healthcare Professionals from the American Heart Association and the American College 
of Cardiology. Circulation, 100, 1481-1492. https://doi.org/10.1161/01.CIR.100.13.1481

[24] Du, X., McNamee, R. and Cruickshank, K. (2000) Stroke Risk from Multiple Risk Factors Combined with Hypertension: A Primary Care Based Case-Control Study in a Defined Population of Northwest England. Annals of Epidemiology, 10, 380-388. https://doi.org/10.1016/S1047-2797(00)00062-4

[25] Chang, Y.T., Wu, J.L., Hsu, C.C., et al. (2014) Diabetes and End-Stage Renal Disease Synergistically Contribute to Increased Incidence of Cardiovascular Events: A Nationwide Follow-Up Study during 1998-2009. Diabetes Care, 37, 277-285. https://doi.org/10.2337/dc13-0781

[26] Nishi, N., Horikawa, C. and Murayama, N. (2015) Characteristics of Food Group Intake by Household Income in the National Health and Nutrition Survey, Japan. Asia Pacific Journal of Clinical Nutrition, On Line.

[27] Statistics Bureau (2015) Japan Statistical Yearbook 2015. Statistics Bureau, Tokyo.

[28] Huskisson, E., Maggini, S. and Ruf, M. (2007) The Role of Vitamins and Minerals in Energy Metabolism and Well-Being. Journal of International Medical Research, 35, 277-289. https://doi.org/10.1177/147323000703500301

[29] Carr, A. and Frei, B. (1999) Does Vitamin C Act as a Pro-Oxidant under Physiological Conditions? FASEB Journal, 13, 1007-1024.

[30] Zadák, Z., Hyspler, R., Tichá, A., et al. (2009) Antioxidants and Vitamins in Clinical Conditions. Physiological Research, 58, S13-S17.

[31] Burton-Freeman, B. (2000) Dietary Fiber and Energy Regulation. Journal of Nutrition, 130, 272S-275S.

[32] Wolfram, T. and Ismail-Beigi, F. (2011) Efficacy of High-Fiber Diets in the Management of Type 2 Diabetes Mellitus. Endocrine Practice, 17, 132-142. https://doi.org/10.4158/EP10204.RA

[33] Morris, M.C., Sacks, F. and Rosner, B. (1993) Does Fish Oil Lower Blood Pressure? A Meta-Analysis of Controlled Trials. Circulation, 88, 523-533. https://doi.org/10.1161/01.CIR.88.2.523

[34] Kris-Etherton, P.M., Harris, W.S. and Appel, L.J., (2002) Fish Consumption, Fish Oil, Omega-3 Fatty Acids, and Cardiovascular Disease. Circulation, 106, 2747-2757. https://doi.org/10.1161/01.CIR.0000038493.65177.94

[35] Nuttall, F.Q. and Gannon, M.C. (1991) Plasma Glucose and Insulin Response to Macronutrients in Nondiabetic and NIDDM Subjects. Diabetes Care, 14, 824-838. https://doi.org/10.2337/diacare.14.9.824

[36] Ma, Y., Li, Y., Chiriboga, D.E., et al. (2006) Association between Carbohydrate Intake and Serum Lipids. Journal of the American College of Nutrition, 25, 155-163. https://doi.org/10.1080/07315724.2006.10719527

[37] Mensink, R.P., Zock, P.L., Kester, A.D., et al. (2003) Effects of Dietary Fatty Acids and Carbohydrates on the Ratio of Serum Total to HDL Cholesterol and on Serum Lipids and Apolipoproteins: A Meta-Analysis of 60 Controlled Trials. American Journal of Clinical Nutrition, 77, 1146-1155.

[38] Fukuda, Y., Nakamura, K. and Takano, T. (2005) Accumulation of Health Risk Behaviours Is Associated with Lower Socioeconomic Status and Women's Urban Residence: A Multilevel Analysis in Japan. BMC Public Health, 5, 53. https://doi.org/10.1186/1471-2458-5-53

[39] Thompson, P.D., Buchner, D., Pina, I.L., et al. (2003) Exercise and Physical Activity in the Prevention and Treatment of Atherosclerotic Cardiovascular Disease: A Statement from the Council on Clinical Cardiology. Circulation, 107, 3109-3116. https://doi.org/10.1161/01.CIR.0000075572.40158.77

[40] Kaur, J. (2014) A Comprehensive Review on Metabolic Syndrome. Cardiology Research 
and Practice, 2014, Article ID: 943162. https://doi.org/10.1155/2014/943162

[41] Oparil, S., Zaman, M.A. and Calhoun, D.A. (2003) Pathogenesis of Hypertension. Annals of Internal Medicine, 139, 761-776. https://doi.org/10.7326/0003-4819-139-9-200311040-00011

[42] Reaven, G.M. (2011) Relationships among Insulin Resistance, Type 2 Diabetes, Essential Hypertension, and Cardiovascular Disease: Similarities and Differences. Journal of Clinical Hypertension, 13, 238-243. https://doi.org/10.1111/j.1751-7176.2011.00439.x

[43] Walker, A.E. (2007) Multiple Chronic Diseases and Quality of Life: Patterns Emerging from a Large National Sample, Australia. Chronic Illness, 3, 202-218. https://doi.org/10.1177/1742395307081504

[44] Chen, H.Y., Baumgardner, D.J. and Rice, J.P. (2011) Health-Related Quality of Life among Adults with Multiple Chronic Conditions in the United States, Behavioral Risk Factor Surveillance System, 2007. Preventing Chronic Disease, 8, A09.

[45] Nakamura, K., Okamura, T., Kanda, H., et al. (2006) Medical Costs of Patients with Hypertension and/or Diabetes: A 10-Year Follow-Up Study of National Health Insurance in Shiga, Japan. Journal of Hypertension, 24, 2305-2309. https://doi.org/10.1097/01.hjh.0000249711.28769.80

[46] Wadsworth, M.E., Santiago, C.D., Einhorn, L., et al. (2011) Preliminary Efficacy of an Intervention to Reduce Psychosocial Stress and Improve Coping in Low-Income Families. American Journal of Community Psychology, 48, 257-271. https://doi.org/10.1007/s10464-010-9384-Z

[47] Kirkpatrick, S.I. and Tarasuk, V. (2009) Food Insecurity and Participation in Community Food Programs among Low-Income Toronto Families. Canadian Journal of Public Health, 100, 135-139.

[48] Fisher, J.O., Arreola, A., Birch, L.L., et al. (2007) Portion Size Effects on Daily Energy Intake in Low-Income Hispanic and African American Children and Their Mothers. American Journal of Clinical Nutrition, 86, 1709-1716.

[49] Margolius, D., Bodenheimer, T., Bennett, H., et al. (2012) Health Coaching to Improve Hypertension Treatment in a Low-Income, Minority Population. Annals of Family Medicine, 10, 199-205. https://doi.org/10.1370/afm.1369

[50] Thom, D.H., Ghorob, A., Hessler, D., et al. (2013) Impact of Peer Health Coaching on Glycemic Control in Low-Income Patients with Diabetes: A Randomized Controlled Trial. Annals of Family Medicine, 11, 137-144. https://doi.org/10.1370/afm.1443

\section{Submit or recommend next manuscript to SCIRP and we will provide best service for you:}

Accepting pre-submission inquiries through Email, Facebook, LinkedIn, Twitter, etc.

A wide selection of journals (inclusive of 9 subjects, more than 200 journals)

Providing 24-hour high-quality service

User-friendly online submission system

Fair and swift peer-review system

Efficient typesetting and proofreading procedure

Display of the result of downloads and visits, as well as the number of cited articles

Maximum dissemination of your research work

Submit your manuscript at: http://papersubmission.scirp.org/

Or contact fns@scirp.org 